\title{
To pluck or not to pluck: scientific methodologies should be carefully chosen, not 'one size fits all'
}

\author{
Todd E. Katzner, Maria Wheeler, Juan Jose Negro, Yula Kapetanakos, J. Andrew DeWoody, \\ Marton Horvath and Irby Lovette
}

T. E. Katzner (todd.katzner@mail.wvu.edu), Division of Forestry and Natural Resources, West Virginia Univ., Morgantown, WV 26506, USA, and USDA Forest Service, Timber and Watershed Laboratory, Parsons, WV, USA. - M. Wheeler, Dept of Biological Sciences, Duquesne Univ., Pittsburgh, PA 15282, USA. - J. J. Negro, Estación Biológica de Doñana (CSIC), ES-41013 Sevilla, Spain. - Y. Kapetanakos, Dept of Ecology and Evolutionary Biology, Cornell Univ., Ithaca, NY 14853, USA, and Cornell Lab of Ornithology, Fuller Evolutionary Biology Lab, Ithaca, NY 14850, USA. - J. A. DeWoody, Dept of Forestry and Natural Resources, Purdue Univ., West Lafayette, IN 47906, USA. - M. Horvath, MME BirdLife Hungary, Költö U. 21, HU-1121 Budapest, Hungary. - I. Lovette, Cornell Lab of Ornithology, Fuller Evolutionary Biology Lab, Ithaca, NY 14850, USA.

\begin{abstract}
McDonald and Griffith (2011) raise important points in their critique of reliance on feathers as a source of DNA for scientific research. Although those authors are right about many details, their one-size-fits all approach (i.e. prescribing blood draws for avian DNA analyses) obscures bigger picture issues that are of extraordinary relevance to avian biology. We introduce four points to provide alternative perspectives on their commentary. In particular, we feel that a) scientific goals should determine methodologies; b) stress to animals is context specific and blood sampling is not always less stressful to birds than feather plucking; c) feather DNA is too valuable to be ignored, especially when coupled with other analyses that require feathers; and $\mathrm{d}$ ) logistical and other concerns often preclude blood sampling. A one size fits all approach to science is generally short-sighted, be it in regard to the collection of genetic or other samples from birds, or to a suite of other research problems.
\end{abstract}

We were pleased to see the recent commentary on hidden costs of relying on feathers as a source of DNA (McDonald and Griffith 2011). Their work addresses several important concepts of concern to avian science. However, although the authors correctly portray many of the details, we are concerned that the one-size-fits all approach they advocate may obscure bigger-picture issues that are of extraordinary relevance to avian biology. It is our goal to flesh out some of these issues and to ensure that animal welfare committees, peer reviewers and researchers are not given the mistaken impression that there is a single best way to collect avian samples for genetic or other analyses.

We begin by clarifying several key points on which we are in strong agreement with McDonald and Griffith (2011). First, there is no question that bird blood is especially attractive for genetic analyses. In contrast to mammalian red blood cells, the nucleated erythrocytes of birds produce high quality DNA samples that are often of great utility. For example, a single blood drop $(\sim 20 \mu \mathrm{l})$ preserved in ethanol usually yields enough high-quality DNA for the multiple amplifications needed in paternity or demographic studies or ample material for next-generation genomics applications. Second, we strongly agree that plucking of remiges, especially bone-anchored primaries, is a practice that likely has substantial negative impacts to birds. Finally, we agree that ethical concerns are highly significant and that minimizing stress to birds and other research subjects is an important goal.

Where we disagree with McDonald and Griffith (2011) is in interpretation of these points and in how we feel their position impacts the scientific process. We especially wish to clarify four ideas.

\section{Science methodology should be driven by research questions}

We reserve our strongest commentary for the one-size-fits all approach to avian DNA sampling taken by McDonald and Griffith (2011). All ornithological research impacts birds and careful scientists have an ethical mandate to minimize impacts to study organisms in the context of the research question being asked. Thus, for a study of nest locations, capture is not required and spot mapping may be sufficient. Likewise, genetic sampling does not require terminal bleeds, but simply the collection of an appropriate sample that minimizes overall impacts. However, spot mapping, genetic sample collection, and terminal bleeds all impact birds and all are appropriate tools to use to address specific research questions. Thus, it is inappropriate to make blanket 
statements, as do McDonald and Griffith (2011), that 'the practice of feather plucking or clipping should be strongly discouraged on both scientific and ethical grounds'. Rather, the correct technique to use is that which best answers the scientific questions being asked.

McDonald and Griffith (2011) also are incorrect to state that 'readers should note that many of the issues raised herein apply to all eventual uses of data obtained via feather sampling...'. In fact, analyses of many types - for stable isotope data (Yohannes et al. 2011), for contaminants (Bechard et al. 2009), or for the stress hormones (Bortolotti et al. 2008) - provide dramatically different insight into organismal biology depending on the origin of the sample considered. A recent and emphatic example of the utility of different data sources comes from work showing variation in lead levels of feathers and of blood from California condors Gymnogyps californianus (Finkelstein et al. 2010). This work, as well as other studies involving multiple analyses derived from a single feather (Lambertucci et al. 2011), would have been precluded by the one-size-fits all approach advocated by McDonald and Griffith (2011). Combining genetics, stress, contaminants and inference from stable isotope work across the multiple time scales provided by multiple sampling approaches is, simply put, an astoundingly valuable tool for the modern avian ecologist. Accordingly, we believe that there is no single best way to approach genetic or other sample collection for research and that general methodological prescriptions (e.g. blood draws instead of feather plucking) have substantial drawbacks.

\section{Stress is context specific}

McDonald and Griffith (2011) demonstrate circumstances where plucking has greater impacts on birds than blood draws. However, there are numerous other circumstances where feather plucking is less impactful and more appropriate than blood draws.

Three of us (Katzner, Negro and Horvath) conduct research on birds of prey and regularly collect genetic samples from raptor chicks in hard-to-climb nest sites in trees, cliffs or tall buildings. To collect a blood sample from such a nestling requires that the bird be carried down to the ground and processed for a prolonged period (often $30 \mathrm{~min}$ or longer). Such processing is stressful for birds and may have extensive health-related consequences (Ferrer and Hiraldo 1995). In contrast, a lone climber can rapidly ascend to a nest, pluck a small growing body feather from a nestling, store it in a collection vial and return to the ground with substantially less risk to the bird and to the researcher than would be feasible if blood sampling were mandated. Along similar lines, a recent study of lesser kestrels Falco naumanni focused on collection of blood during the breeding season and feathers during the non-breeding season specifically to minimize disturbance to the birds (Rodríguez et al. 2011). The one-size fits all perspective of McDonald and Griffith (2011) appears to preclude either of these approaches.

In fact, the best and least stressful tool for sample collection is often case-specific. Once a bird is in the hand, blood draws are still time consuming and require greater handling than does a quick feather pluck. Handling time greater than two to five minutes (often a minimum required to draw blood) is long enough to elicit an acute stress response, as indicated by rising blood corticosterone levels (Hood et al. 1998, Vleck et al. 2000, Sockman and Schwabl 2001). High corticosterone levels can cause a wide range of effects from alterations to basic behavior and metabolism (Cockrem 2007) to delayed growth in the offspring of a stressed laying female (Hayward and Wingfield 2004). Likewise, there are a number of other scenarios where blood sampling is the more intensive and stressful way to collect a genetic sample from a bird. Thus, blood sampling can be either more or less stressful than feather sampling, and there is no clearcut rule to follow. One should not throw out the baby of science with the bathwater of negative impacts.

\section{Feather DNA quality is variable but feathers are too valuable to be ignored}

We agree that feathers can produce less quality and quantity of DNA than do blood samples, but there is extensive variability in outcomes of feather analysis. In fact, as technology has advanced, feather sampling results have improved with time, as tools are developed and as new details on feather analysis are described (Horvath et al. 2005, Hogan et al. 2007). Thus, the low quality of genetic materials reported in some studies is cause for increased attention to the problem of better DNA extractions, but not cause for eliminating a potentially useful technique wholesale.

As we noted earlier, we agree with McDonald and Griffith's (2011) concern about plucking primaries. However, for many birds, including passerines, primaries are not required for collection of significant genetic material. In fact, feathers only centimeters long may come from any part of the bird and can provide useful DNA; plucking a body feather is unlikely to have any substantial impact on bird physiology or survival. As lab techniques continue to improve (Morin and McCarthy 2007, Rowe et al. 2011), we anticipate that the difference in quality and quantity of DNA extracted from feathers and blood will continue to diminish, making this point even less relevant.

\section{Expediency, feasibility and logistical concerns}

Feather sampling not only is a fast and easy way to collect a sample, but it can also be especially attractive in remote field settings with limited facilities for storing perishable blood samples. Once collected, feathers can be kept at room temperature if housed properly (Rudnick et al. 2009). Blood samples require either refrigeration or a cocktail of buffers and a backpack of supplies at the ready, including needles and syringes, storage tubes and buffers, as well as cotton balls and pharmaceuticals to handle emergencies. When combined with the need for suitable training to draw blood, the hurdles to blood sampling in the field can often be substantially greater than those for feather sampling.

Real-world logistical considerations also play a role in sampling design, as sampling protocols are often influenced by policies and regulations that are outside the control of the 
research group. For example, laws that forbid certain sampling approaches or that hinder export of blood or feather samples are common globally. Although these external policies may sometimes be misguided, they can place real constraints on the types of material that can be gathered. At the same time, it is incumbent on researchers to educate policy makers (including review boards and permitting authorities) wherever possible about the rationale behind alternative sampling protocols. It is also important that researchers avoid defaulting to a suboptimal but easier sampling strategy simply because it is expedient, when an alternative protocol that would result in a more useful sample is feasible. These kinds of decisions must be made on a case-by-case basis after weighing the costs and benefits of alternative approaches.

Researchers taking either feathers or blood samples should be aware that these types of unvouchered materials are far from ideal for some types of research. Particularly in the systematics community, unvouchered genetic samples are generally viewed as very poor (and often unacceptable) substitutes for tissue samples that are backed by a traditional museum specimen. Furthermore, properly frozen tissues allow additional classes of analysis not possible with other types of samples, such as RNA-based tests of gene expression patterns. Yet fully vouchered frozen tissue samples are clearly unobtainable in some research situations, perhaps most notably when the research objectives include tracking the future behavior or fitness of the birds sampled! The point once again is simply that no one sampling method is optimal in all circumstances; a common sense choice of sampling protocol should always be based on the overall research goals, including whether the samples are intended for long-term archiving towards future - and perhaps presently unknown - types of research.

\section{Conclusions}

In closing, our commentary is intended to emphasize a couple of key ideas. First, research methodology should depend on the specific research questions being asked, not on general prescriptions. Blanket policies impede the development of science and hinder researchers in pursuit of socially important conservation and research goals. Second, stress to animals and research goals are context specific. Animal use committees, peer-reviewers and scientists should evaluate each case separately to identify the most appropriate sampling tool for each situation. Finally, in spite of the high quality of DNA in bird blood, feathers can provide important and useful DNA. Furthermore, feathers can provide information beyond what may be simply collected from blood, including materials for stable isotope and unique hormone and contaminant analyses. A 'one-size-fits all' approach to science may be well intentioned but is generally short-sighted. This applies to collection of genetic or other samples from birds, as well as to a suite of other research problems.

Acknowledgements - Comments of Alfonso Marzal and Staffan Bensch improve earlier versions of the manuscript.

\section{References}

Bechard, M., Perkins, D. N., Kaltenecker, G. S. and Alsup, S. 2009. Mercury contamination in Idaho bald eagles, Haliaeetus leucocephalus. - Bull. Environ. Contam. Toxicol. 83: 698-702.

Bortolotti, G., Marchant, T. A., Blas, J. and German, T. 2008. Corticosterone in feathers is a long-term, integrated measure of avian stress physiology. - Funct. Ecol. 22: 494-500.

Cockrem, J. F. 2007. Stress, corticosterone responses and avian personalities. - J. Ornithol. 148: S169-S198.

Ferrer, M. and Hiraldo, F. 1995. Human-associated staphylococcal infection in Spanish imperial eagles. - J. Wildl. Dis. 31: 534-536.

Finkelstein, M., George, D., Scherbinski, S., Gwiazda, R., Johnson, M., Burnett, J., Brandt, J., Lawrey, S., Pessier, A. P., Clark, M., Wynne, J., Grantham, J. and Smith, D. R. 2010. Feather lead concentrations and ${ }^{207} \mathrm{~Pb} /{ }^{206} \mathrm{~Pb}$ ratios reveal lead exposure history of California condors (Gymnogyps californianus). - Environ. Sci. Technol. 44: 2639-2647.

Hayward, L. S. and Wingfield, J. C. 2004. Maternal corticosterone is transferred to avian yolk and may alter offspring growth and adult phenotype. - Gen. Comp. Endocrinol. 135: 365-371.

Hogan, F. E., Cooke, R., Burridge, C. P. and Norman, J. A. 2007. Optimizing the use of shed feathers for genetic analysis. - Mol. Ecol. Not. 8: 561-567.

Hood, L. C., Boersma, P. D. and Wingfield, J. C. 1998. The adrenocortical response to stress in incubating Magellanic penguins (Spheniscus magellanicus). - Auk 115: 76-84.

Horvath, M. B., Martınez-Cruz, B., Negro, J. J., Kalmar, L. and Godoy, J. A. 2005. An overlooked DNA source for noninvasive genetic analysis in birds. - J. Avian Biol. 36: 84-88.

Lambertucci, S. A., Donázar, J. A., Delgado Huertas, A., Jiménez, B., Sáez, M., Sanchez-Zapata, J. A. and Hiraldo, F. 2011. Widening the problem of lead poisoning to a South American top scavenger: lead concentrations in feathers of wild Andean condors. - Biol. Conserv. 144: 1464-1471.

McDonald, P. G. and Griffith, S. C. 2011. To pluck or not to pluck: the hidden ethical and scientific costs of relying on feathers as a primary source of DNA. - J. Avian Biol. 42: 197-203.

Morin, P. A. and McCarthy, M. 2007. Highly accurate SNP genotyping from historical and low-quality samples. - Mol. Ecol. Not. 7: 937-946.

Rodríguez, A., Alcaide, M., Negro, J. J. and Pilard, P. 2011. Using major histocompatibility complex markers to assign the geographic origin of migratory birds: examples from the threatened lesser kestrel. - Anim. Conserv. 14: 306-313.

Rowe, K. C., Singhal, S., MacManes, M. D., Ayroles, J. F., Morelli, T. L., Rubidge, E. M., Bi, K. and Moritz, C. C. 2011. Museum genomics: low-cost and high-accuracy genetic data from historical specimens. - Mol. Ecol. Resour. 11: 1082-1092.

Rudnick, J. A., Katzner, T. E. and DeWoody, J. A. 2009. Genetic analyses of noninvasively collected feathers can provide new insights into avian demography and behavior. - In: Aronoff, J. B. (ed.), Handbook of nature conservation. Nova Science Publishers, pp. 181-197.

Sockman, K. W. and Schwabl, H. 2001. Plasma corticosterone in nestling American kestrels: effects of age, handling stress, yolk androgens, and body condition. - Gen. Comp. Endocrinol. 122: 205-212.

Vleck, C. M., Vertalino, N., Vleck, D. and Bucher, T. L. 2000. Stress, corticosterone, and heterophil to lymphocyte ratios in free-living Adélie penguins. - Condor 102: 392-400.

Yohannes, E., Lee, R. W., Jochimsen, M. C. and Hansson, B. 2011. Stable isotope ratios in winter-grown feathers of great reed warblers Acrocephalus arundinaceus, clamorous reed warblers $A$. stentoreus and their hybrids in a sympatric breeding population in Kazakhstan. - Ibis 153: 502-508. 